\title{
Coupled Reactor Kinetics and Heat Transfer Model for Heat Pipe Cooled Reactors
}

\author{
Steven A. Wright ${ }^{1}$, Michael Houts ${ }^{2}$ \\ Sandia National Laboratories, MS-1146, PO Box 5800, Albuquerque NM, $87185^{1}$ \\ NASA/Marshall Space Flight Center, TD40, Huntsville, Alabama, $35812^{2}$ \\ 505-845-3014 sawrigh@ sandia.gov ${ }^{1}$,256-544-7143 michael.houts@msfc.nasa.gov ${ }^{2}$
}

\begin{abstract}
Heat pipes are often proposed as cooling system components for small fission reactors. SAFE-300 and STAR-C are two reactor concepts that use heat pipes as an integral part of the cooling system. Heat pipes have been used in reactors to cool components within radiation tests (Deverall, 1973); however, no reactor has been built or tested that uses heat pipes solely as the primary cooling system. Heat pipe cooled reactors will likely require the development of a test reactor to determine the main differences in operational behavior from forced cooled reactors. The purpose of this paper is to describe the results of a systems code capable of modeling the coupling between the reactor kinetics and heat pipe controlled heat transport. Heat transport in heat pipe reactors is complex and highly system dependent. Nevertheless, in general terms it relies on heat flowing from the fuel pins through the heat pipe, to the heat exchanger, and then ultimately into the power conversion system and heat sink. A system model is described that is capable of modeling coupled reactor kinetics phenomena, heat transfer dynamics within the fuel pins, and the transient behavior of heat pipes (including the melting of the working fluid). The paper focuses primarily on the coupling effects caused by reactor feedback and compares the observations with forced cooled reactors. A number of reactor startup transients have been modeled, and issues such as power peaking, and power-to-flow mismatches, and loading transients were examined, including the possibility of heat flow from the heat exchanger back into the reactor. This system model is envisioned as a tool to be used for screening various heat pipe cooled reactor concepts, for designing and developing test facility requirements, for use in safety evaluations, and for developing test criteria for in-pile and out-of-pile test facilities.
\end{abstract}

\section{INTRODUCTION}

Heat pipes have been proposed for use in numerous space nuclear reactors concepts. At Marshall Space Flight Center a current reactor concept being developed for rapid demonstration is SAFE-300 (Poston 2001). This concept uses sodium or lithium heat pipes that are integral with the reactor fuel pins and coupled to a heat exchanger. Effectively, the heat pipes are used as the primary cooling mechanism for the reactor. Other reactor designs have also used heat pipes as integral parts of the space nuclear power systems. These include STAR-C and SP-100 (ref, ref). STAR-C used disk shaped annuli of uranium carbide supported in graphite rings that were thermally directly coupled to thermionic converters. The converters were in turn radially coupled directly to heat pipe radiator segments each covering a small azimuthal section of the reactor core. Also, SP-100 proposed to cool the reactor with pumped lithium which provided heat to the hot side of thermo-electric converter module that was cooled with a potassium heat pipe radiator.

The primary difference between these three concepts is the number of layers of intermediate materials or sub-systems between the reactor fuel and the heat pipe. SAFE-300 uses heat pipes as the primary cooling mechanism having the heat pipes directly coupled to the fuel pins. STAR-C has only the thermionic converter as an intermediary material between the heat pipe and the fuel, while SP-100 cooled the reactor conventionally with forced pumped lithium which then heated the hot leg of the thermo-electric converters. Heat pipes were used to reject the excess heat through a heat pipe radiator. These different arrangements 


\section{DISCLAIMER}

This report was prepared as an account of work sponsored by an agency of the United States Government. Neither the United States Government nor any agency thereof, nor any of their employees, make any warranty, express or implied, or assumes any legal liability or responsibility for the accuracy, completeness, or usefulness of any information, apparatus, product, or process disclosed, or represents that its use would not infringe privately owned rights. Reference herein to any specific commercial product, process, or service by trade name, trademark, manufacturer, or otherwise does not necessarily constitute or imply its endorsement, recommendation, or favoring by the United States Government or any agency thereof. The views and opinions of authors expressed herein do not necessarily state or reflect those of the United States Government or any agency thereof. 


\section{DISCLAIMER}

Portions of this document may be illegible in electronic image products. Images are produced from the best available original document. 
lead to very different temperature distributions (axial and radially) within the reactor. Because heat pipes are essentially constant temperature devices, their contact with the fuel will lead to nearly constant temperature fuel along the evaporation/condensation axis of the heat pipe. Depending on how the heat pipe is cooled (via a heat exchanger or radiator), the entire length of the fuel could be at or near the same temperature. This will have both positive and negative reactor design consequences. The positive aspect is that it might be possible to arrange to have the core operate at near constant temperature at the design power. This phenomenon might be used to reduce differential expansion stresses within the fuel pins and support structure. Alternatively, it also might mean that the entire core is operating at near the maximum fuel temperature. This would introduce added design difficulties because there are no "cold" regions to take advantage of and could limit the overall life of the reactor due to higher average material temperatures. In addition the thermal mechanical response of the fuel pins in heat pipe reactors will produce different fuel pin bowing behavior than in forced cooling designs.

Other potential positive attributes of heat pipe cooled reactors include modularity, testability, simplified system integration, and the elimination of single-point failures. In the SAFE-300 design, the core is composed of individual heat pipe modules. Because most system engineering challenges for this design are associated with the module design and its performance, significant development and verification work can be performed at a module level. Therefore, successful module development and testing represents a major step towards developing a viable system, and it can be accomplished in a timely and affordable fashion. Because heat pipe cores do not require a coolant plenum, fuel pins are more accessible from outside of the reactor. It may thus be easier to perform full power tests on actual flight units using resistance heaters to closely mimic heat from fission. Following the full power (resistance heated) tests of the flight unit, only relatively simple operations are required to remove the heaters, insert fissile fuel, and ready the system for launch. Testability of the flight unit is a very important attribute for verifying system reliability prior to launch. System integration issues can be less for heat pipe cooled systems because many components required for pumped-loop systems are eliminated. Components that are eliminated include pumps, thaw systems, gas separators, and complicated pressure vessels. Finally, heat pipe cores can be designed to deliver rated power even following multiple heat pipe failures.

This paper describes a system model that couples reactor kinetics, fuel pin heat transfer, heat pipe thermal transport, and power conversion to study the operational and dynamic behavior of reactors cooled directly by heat pipes. This type of system model is needed because the reactor temperature is directly coupled to the reactor reactivity, and thus it is also coupled to the power level through feedback mechanisms. The development of such a model is important because no reactor has ever been built and tested that uses heat pipes either directly or indirectly as the primary cooling method. This system model is envisioned as a tool to be used for screening various heat pipe cooled reactor concepts, for designing and developing test facility requirements, for use in safety evaluations, and for developing test criteria for in-pile and out-ofpile test facilities.

\section{GENERAL DESCRIPTION OF SYSTEM MODEL FOR HEAT PIPE COOLED REACOTRS (PKHP1D)}

A system code was developed to study the kinetic behavior or heat pipe cooled reactors. The code is called PKHP1D (Point Kinetics for Heat Pipe reactors with 1 Dimensional heat transport). It is loosely based on a similar code PK1D (Pickard, 1977) that was used to determine the operational characteristics of the Sandia National Laboratories ACRR pulse reactor (Reuscher, 1979). PKHP1D is written in Fortran 90 and consists of a number of separate subroutine modules for:

- Reactor kinetics (PK1DHP),

- Fuel pin one-dimensional radial heat transport module (fpHeatTransfer),

- Material properties (MatProp),

- Input, output, and plotting,

- Heat pipe thermal transport and kinetic behavior (hpHeatTransfer),

- Heat exchanger thermal transport, (XHeatTransfer), and

- Power Conversion thermal transport and fluid flow behavior ( $\mathrm{pcHeatTransfer).}$

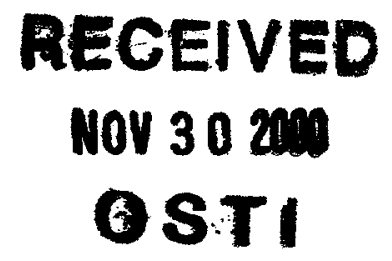


The reactor kinetics and the fuel pin heat transfer routines are fully operational. However the heat pipe and the power conversion systems are currently implemented as very simple ideal systems. The heat exchanger is implemented as a pseudo-steady-state single temperature node device. Even though some of the modules have limited capability, the complete code is functional and interfaces to text and plot output programs that already allow observation of the reactor system behavior. Particular attention has been given to studying the startup sequence for the SAFE-300. Startup scenarios are particularly important (and will become even more relevant once a realistic heat pipe module is input into the code) as it requires melting of the liquid metal and transitioning the heat pipe from sonic limited conditions to a fully operational state.

A general description of the system model is illustrated in Figure 1. The standard point reactor kinetics equations with six delayed neutron groups are solved to determine the reactor power given a specified input reactivity. The total reactivity is determined by including the core average temperature feed back effect as

$$
\rho_{\text {total }}=\rho_{\text {insert }}-\alpha T_{\text {coreAverage }}
$$

where $\alpha$ is the negative feedback coefficient (on the order of $0.1-0.3 \not / \mathrm{K}$ ), $\beta$ is the delayed neutron fraction, and $\rho / \beta=1 \$$ worth of reactivity), $\rho_{\text {insert }}$ is the reactivity inserted by the control system and $T_{\text {coreAverage }}$ is the core average temperature. (Other reactivity terms can be included, such as thermal expansion, bowing effects, or coolant void fractions, if one knows how they depend on the core average or local temperature.) The fuel pins are modeled in regions having constant radial and axial power profiles as well as constant pin to core average power densities within a region. Each region consists of a specified number of fuel pins and heat pipes within unit cells. For each region the user must input the number of unit cells, the number of pins and heat pipes per unit cell. Within each region, the heat pipes are assumed to extend into the heat exchanger and operate at the same power and temperature. In the heat exchanger the code assumes that the thermal and fluid flow properties (heat pipe temperature, region mass flow rate, and inlet and outlet temperatures) are constant. The current heat exchanger model uses a single heat pipe temperature per region, a specified mass flow rate (chosen to match power to flow at the designed operating temperature), and a specified inlet coolant flow temperature.

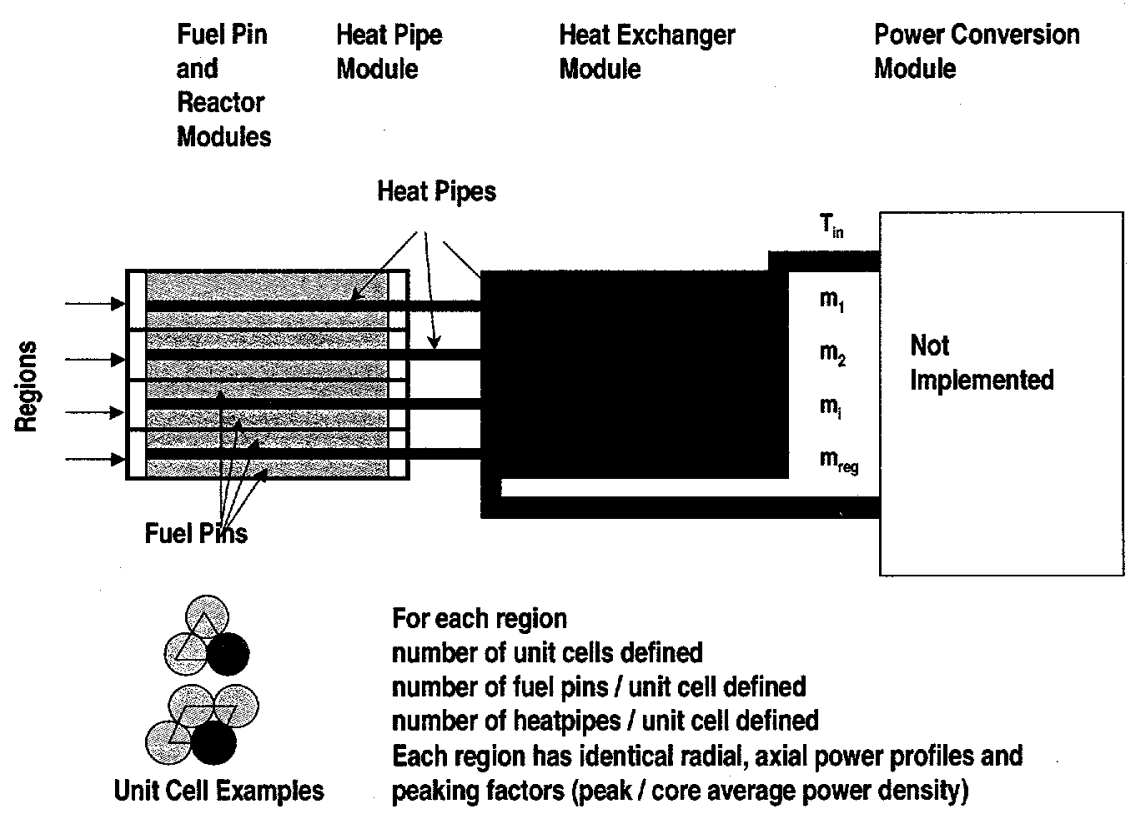

FIGURE 1. Modules in PKHP1D modeling the reactor, fuel pins, heat pipes, heat exchanger, and power conversion system. Within each region of the reactor the number of pins per unit cells, the number of unit cells, and the number of heat pipes per unit cell must be defined. The region peak to core average power density is constant, as are the radial and axial power profiles. The heat exchanger has the same number of regions as does the reactor. The inlet temperature and mass flow rate are specified for each region in the heat exchanger. 


\section{SAFE-300 IMPLEMENTATION IN PKHP1D}

\section{Reactor Description}

This section describes the SAFE-300 implementation in PKHP1D. Figure 2 shows a cross section of the SAFE-300 core with its radial reflectors. Note that the reactor core is modeled with 273 and 106 heat pipes. The fuel pins are divided into three regions with a region pin power to average pin power ratio of $1.0,1.3$. and 1.5. (Small highly reflected reactor systems can have radial power density profiles that peak near the radial reflector, though SAFE-300 has a relatively flat radial power profile.) The peak factors and other parameters used in this paper are simply estimates of the real SAFE-300 reactor parameters and were not obtained by performing detailed neutron transport calculations.) Figure 3 describes the geometry, dimensions, materials and number of nodes used to model the fuel pin radial conduction including its contact (assumed perfect) with the heat pipe. Each fuel pin uses $\mathrm{UO}_{2}$ fuel that is clad in Molybdenum. The cladding outside diameter is $12 \mathrm{~mm}$. Figure 4 shows an axial cross section of the reactor illustrating that the reactor fuel length is $0.45 \mathrm{~m}$ and the core diameter is $0.42 \mathrm{~cm}$. The reactor temperature feed back coefficient was taken to be negative $0.1 \phi / \mathrm{K}$ the neutron generation time was set at $1 \mu \mathrm{sec}$, and the delayed neutron fraction was .006449 . These reactor kinetics parameters need to be determined by separate neutron transport calculations.

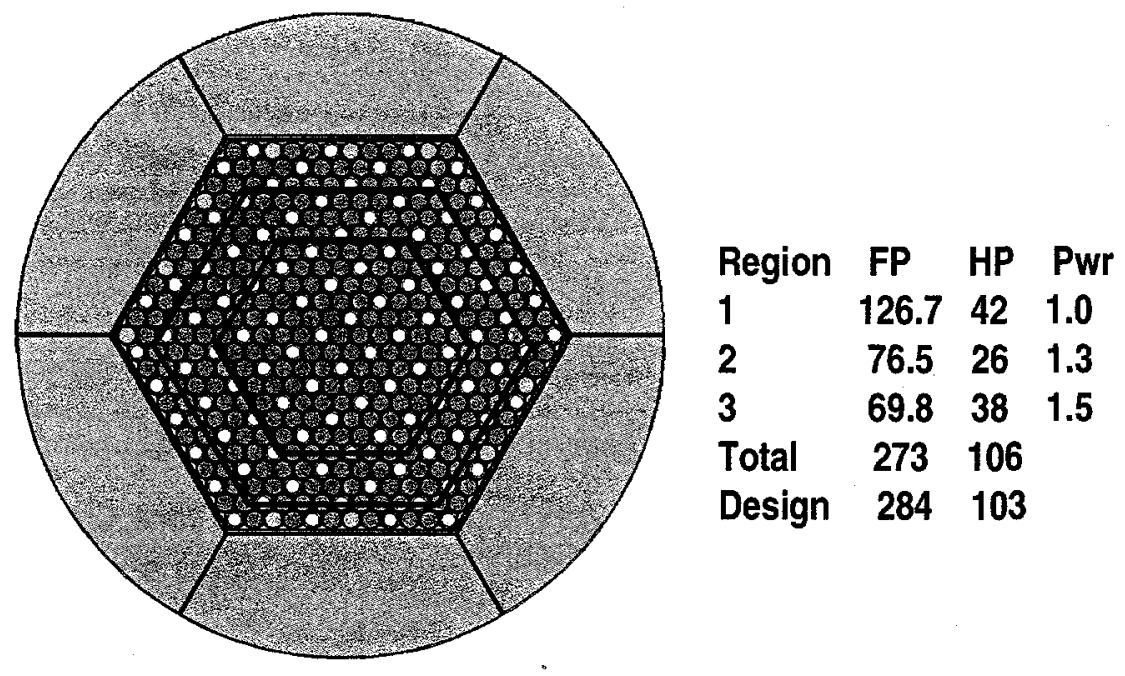

Figure 2. SAFE-300 implementation in PKHP1D includes 3 regions. Region 1 has 126.7 fuel pins, 42 heat pipes and a pin average power density to core average power density of 1.0 for the first (central) region.

The heat pipe model is illustrated in Figure 5 and is currently limited to a very ideal system. The model assumes that the heat pipe operates at a constant temperature along the length and that the heat into the heat pipe equals the heat exiting the heat pipe. For an operational heat pipe this is not too bad of an approximation. However, it greatly over simplifies the start up characteristics of a liquid metal heat pipe. A more realistic version of the heat pipe will be included in future versions of the code. 


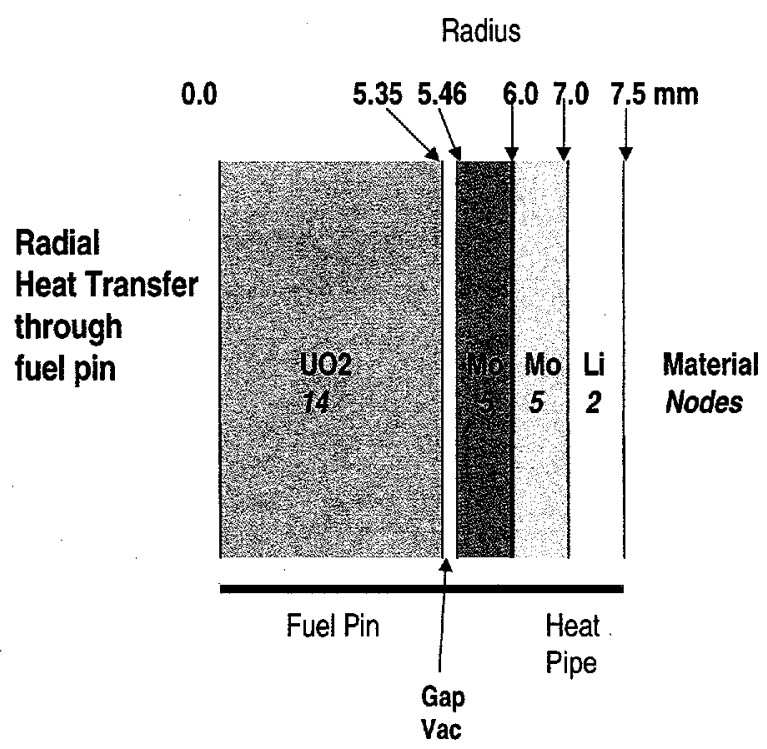

Figure 3. Radial geometry of fuel pins and heat pipes. All pins have the same geometry in each region.

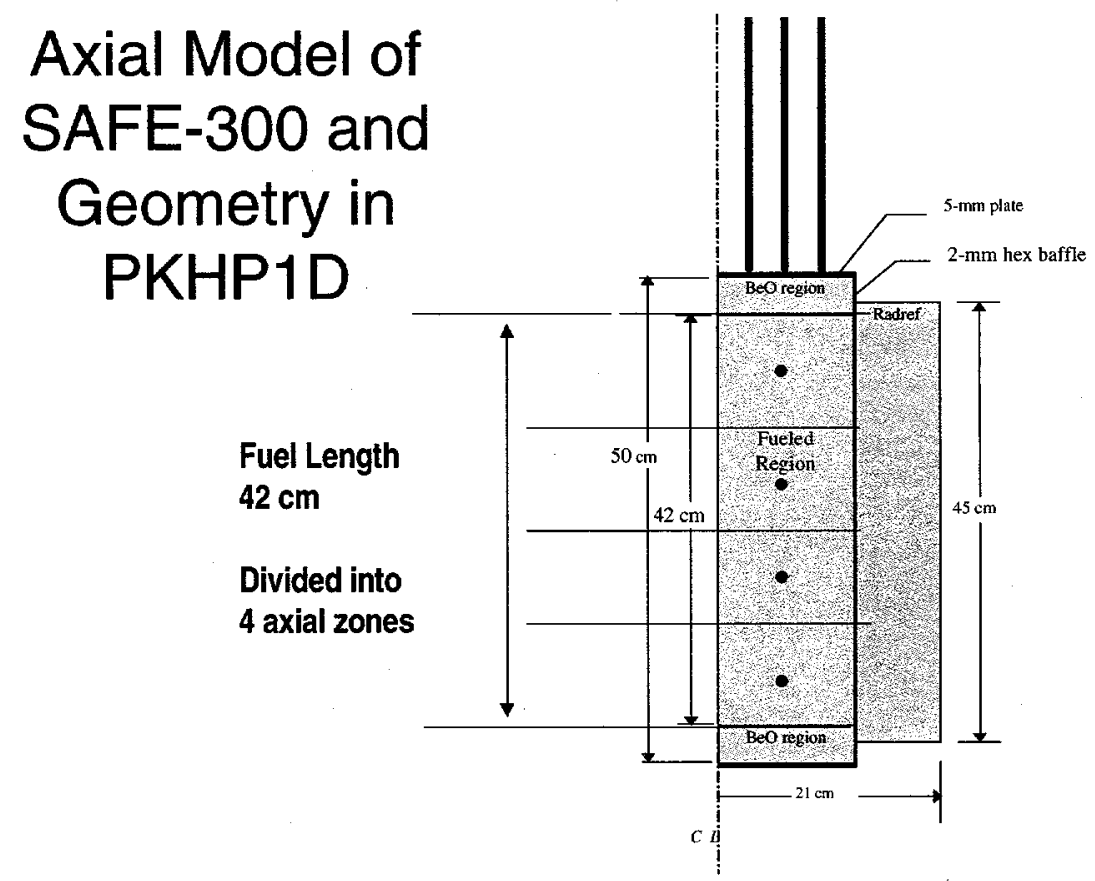

Figure 4. Axial model for SAFE-300. PKHP1D breaks the core into four axial zones having constant power densities. 


\title{
Heat Pipe Module
}

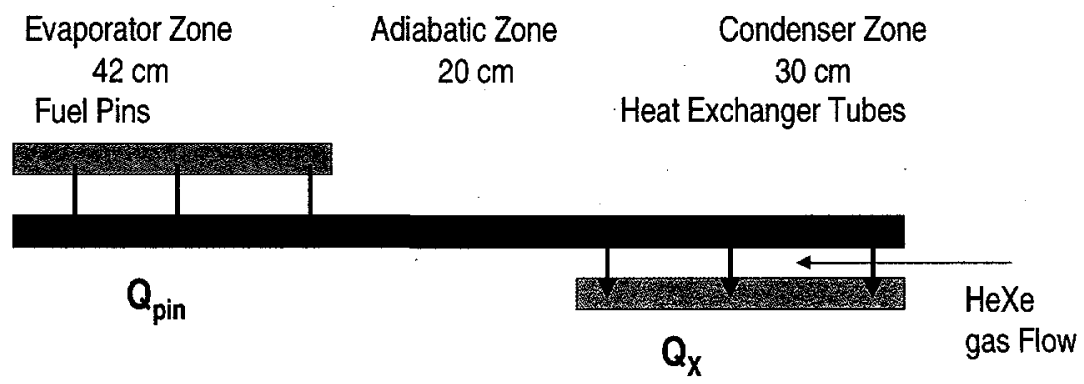

\author{
$Q_{\text {pin }}=Q_{X}$ Heat Flow in Pin and $H X$ are equal \\ Heat Flux from pin to HP determined by dT/dr in HP wall \\ Heat flux from HP to HX gas flow is determined by heat transfer coefficient \\ Heat transfer coefficient is a Dittus Boetler like correlation $\mathrm{Nu}=\mathrm{A} \mathrm{Re}^{\mathrm{a}} \mathrm{Pr}^{\mathrm{b}}$
}

FIGURE 5. Heat pipe module currently implemented in PKHP1D. It assumes that the heat pipe is at constant temperature along its length and that the heat into the heat pipe equals the heat out.

\section{PKHP1D Startup Scenario for SAFE-300}

This section of the report briefly describes a startup scenario for SAFE-300. The input and results of the startup sequence are illustrated in Figure 6a-d. This startup scenario was based on a very slow startup that was used for SNAP-10a (Johnson, 1967). The startup begins with a step reactivity insertion of 12ф, followed by a wait of $1000 \mathrm{~s}$. After the $1000 \mathrm{~s}$, the reactivity is inserted at a rate of $.03 \notin / \mathrm{s}$ until $\mathrm{t}=5600 \mathrm{~s}$ at which point $\$ 1.50$ worth of reactivity has been inserted into the reactor. This inserted reactivity is shown in figure 6a. During startup the power conversion system supplies gas to the heat exchanger at $225 \mathrm{~K}$ at mass flow rate $0.25 \mathrm{~kg} / \mathrm{s}(\mathrm{He} / \mathrm{Xe})$. At about $1000 \mathrm{~s}$ the reactor power level reaches about $40 \mathrm{~kW}$ which is sufficiently high to provide enough reactor heating so that the negative feedback slows the increase in power. As reactivity is still being inserted the reactor power level and temperature continues to increase and eventually they reach $100 \mathrm{~kW}$ and $900 \mathrm{~K}$ at $3000 \mathrm{~s}$. Notice that during this time (1000-3000s) the reactor core average temperature is gradually heating up at a near constant rate. When the reactor temperature reaches $900 \mathrm{~K}$ (at which point the heat pipes should be fully operational and the temperature should be large enough to support operation of a closed Brayton cycle power conversion system), the power conversion system turns on. This will temporarily cool the reactor and add more reactivity (due to negative feedback) to meet the power demand of the power conversion system. While the power conversion system is turning on (by slowly increasing inlet temperature to the heat exchanger and by increasing the mass flow rate through the heat exchanger, 3000-3800s), the reactor power level, temperature, and reactivity oscillate around a constant rate or level until the system automatically matches reactor power to demand power. Eventually reactor and heat exchanger power match each other at near full power $(330 \mathrm{~kW})$ with a maximum core temperature of $1400 \mathrm{C}$. A close examination of this power history will show a very strong resemblance to that observed in the SNAP-10 startup (Johnson, 1967). The oscillations in power shown in the figures are real and are a result of the coupling between the reactor temperature, the reactivity feedback, and the flow through the heat exchanger. 

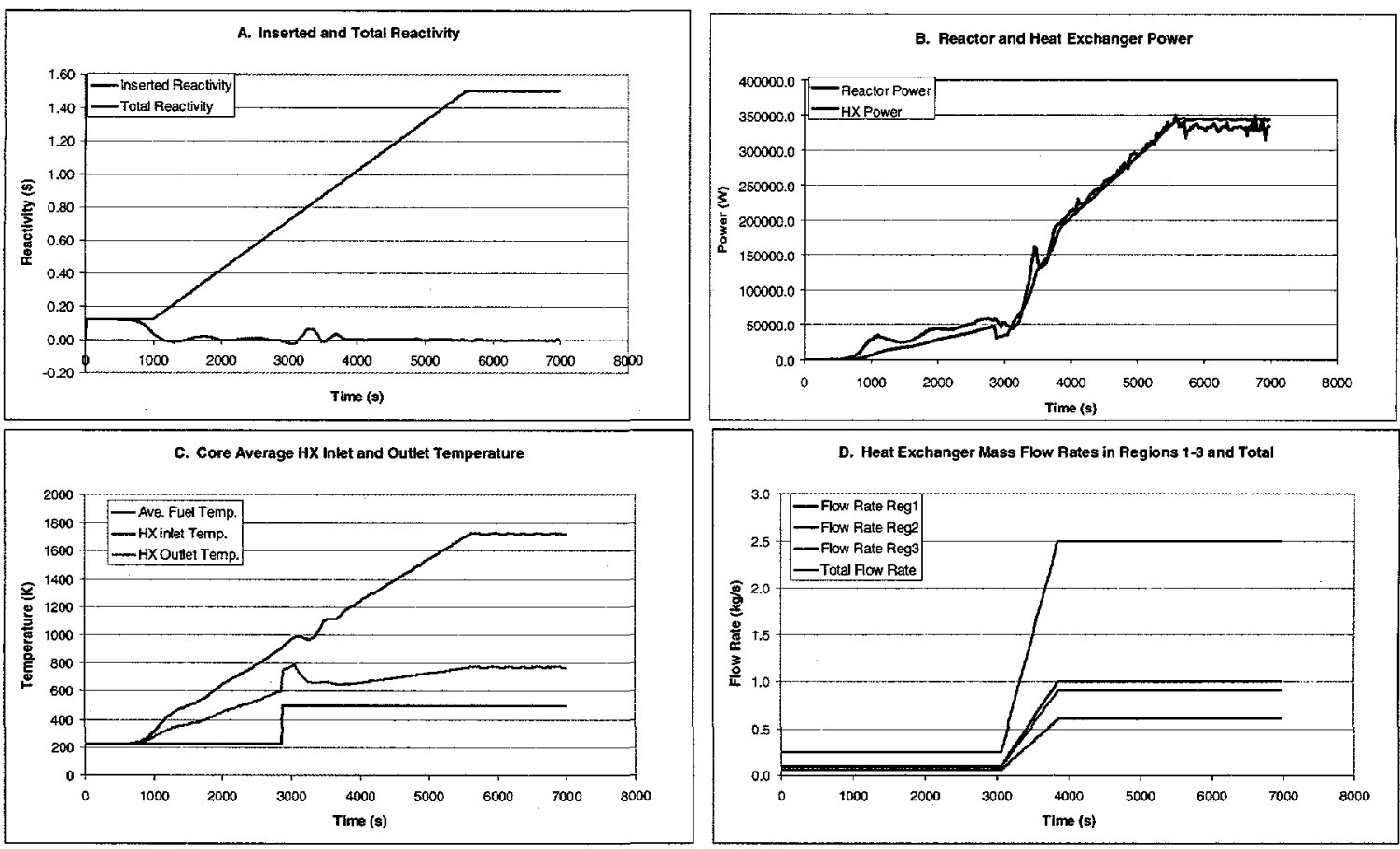

FIGURE 6. Plots of the start up transient for SAFE-300. Figure a shows the inserted and total reactivity curves. Figure $b$ shows the reactor power and the heat transferred in the heat exchanger, figure $c$ shows the core average temperature, the HX gas inlet and outlet temperatures, and figure $\mathbf{d}$ shows the mass flow rates through the heat exchanger.

\section{CONCLUSIONS}

This report describes the results of a system code (PKHP1D) capable of modeling the coupling between the reactor kinetics and heat pipe controlled heat transport. A system model is described that is capable of modeling coupled the reactor kinetics phenomena, heat transfer dynamics within the fuel pins, and the transient behavior of heat pipes (including the melting of the working fluid). The paper focuses primarily on the coupling effects caused by reactor feedback and compares the observations with forced cooled reactors. A number of reactor startup transients were modeled. A brief summary of a realistic startup transient similar to that used in the SNAP-10a flight was described. This system model is envisioned as a tool to be used for screening various heat pipe cooled reactor concepts, for designing and developing test facility requirements, for use in safety evaluations, and for developing test criteria for in-pile and out-ofpile test facilities.

\section{ACKNOWLEDGEMENTS}

This work was performed while the author S. Wright was on an Individual Personnel Assignment from Sandia National Laboratories to NASA Marshall Space Flight Center. S. Wright acknowledges George Schmidt, Philisha Matthews, Melissa Vandyke, and the staff at Propulsion Research Center/TD40. 


\section{REFERENCES}

Anderson, R. V., et. al., "Space-Reator Electric Systems: Subsystem Technology Assessment", Rockwell International, ESG-DOE-13398, DE83 01308, March 1983.

Begg, L.L.; Wuchte, T.J.; Otting, W.D., "Star-C thermionic space nuclear power system", General Atomics, San Diego, CA, USA, AIP Conference Proceedings, no.246, pt.1, p.114-19, 1992.

Deverall, J. E., "Heat Pipe Thermal Control of Irradiation Capsules", First International Heat Pipe Conference, Stuttgart, West Germany, October 15-17, LA-UR-73-1033 or Conf-731025-1, 1973.

Johnson, R. A., Morgan, W. T., et. al., "Design, Ground Test, and Flight Test of SNAP 10A, First Reactor in Space", Nuclear Engineering and Design, Vol. 5, pp7-20, 1967.

Mondt, Jack F., "SP-100 Technical Summary Report", Volume II, Technical Report, JPL D-11818, September 1994.

Hetrick, David L., Dynamics of Nuclear Reactors, University of Chicago Press, Chicago and London, 1971.

Pickard, Paul S., Jay P. Odom, "Reactor Kinetics Codes, SAK and PK1D", Sandia National Laboratories, SAND771211,1977

Poston, D. I., Et al. (2001) "Nuclear Design of SAFE-30 and SAFE-300 Reactors", to be published in STAIF-2001 Proceedings.

Reuscher Jon A., Design and Performance Characteristics of the Annular Core Research Reactor (ACRR), SAND790129A, January, 1979. 